\title{
Dynamic pricing research on perishable products under consumer strategy behaviour
}

\author{
Li Zhou ${ }^{1,}$, Jing $\mathbf{L i}^{2}$ \\ ${ }^{1}$ School of Information, Beijing Wuzi University, Beijing, China \\ ${ }^{2}$ Graduate department, Beijing Wuzi University, Beijing, China
}

Email address:

zhoulibit@126.com (Li Zhou)

To cite this article:

Li Zhou, Jing Li. Dynamic Pricing Research on Perishable Products under Consumer Strategy Behaviour. Science Journal of Applied Mathematics and Statistics. Vol. 2, No. 4, 2014, pp. 78-84. doi: 10.11648/j.sjams.20140204.12

\begin{abstract}
It mainly focuses the consumer strategy behavior effect on retailers pricing mechanism. Under the condition of uncertainty demand and deterministic demand, consumers' strategy behavior influence to price and profit. By introducing a discount factor, considering inventory timely complement and fixed inventory in two cases, obtains purchase decision and dynamic pricing strategies of consumers.
\end{abstract}

Keywords: Consumer Strategy, Perishable Products, Dynamic Pricing, Inventory

\section{Introduction}

When the market information environment is sufficient, the consumers purchase goods will be very rational. They through the commercial history information, inventory and sales cycle of perishable products price changes have certain expectations, then consumers will be rational in that can get the big consumer surplus buying goods. Choice in the maximum consumer surplus let consumers wait for the actual phenomenon buy better explain; such enterprises can provide better reference in the process of practical strategies.

In theory, Elmaghraby (2003)[1] considers two kinds of conditions of complete and incomplete information. He establishes a model to study the consumers will buy multiple enterprises products, and the price strategy. With the rapid development of internet transactions, transaction prices, inventories and consumer psychological changes very fast. Zhou(2005)[2] under the condition of complete information, considers the consumer's strategic behavior, further expands the revenue management, and in the continuous time formulates the optimal purchasing strategy. Because the perishable goods value along with the sales cycle of growth, there will be a certain elapse, Aviv (2008)[3] by considering the introduction of a decrements value function of consumer about time, discusses enterprises implement the pricing strategy with fixed inventory.

Peng Zhiqiang(2009b)[4] hypothesis that strategy and myopic consumers exist in the market at the same time, analyzes the dynamic pricing model with strategic consumers, and post compensation mechanism on the retail price and income. Research shows that strategic consumers delay purchase influences the retailer's pricing strategy and makes profit decreases. However, the price difference compensation mechanism can eliminate the delay purchase of strategic customers, and improve the retailer's earnings.

Cheng Yan (2011) [5] redefines the notion of perishable goods, the definition of perishable products are the products that produce long lead times, short sales cycle, unsold goods residual low. In order to reduce the inventory profit and loss of perishable goods, retail sales will dynamic lower commodity price with the end sales approaching. However, the strong price expectations often aggravates delayed purchase behavior of consumers, this delay buying behavior will increase the income of the perishable goods risk retailers. In the rapid development of Internet and e-commerce situation, Dou Jinhu (2011) [6] studies on dynamic pricing for perishable goods retail under network conditions, analyzes the strategy consumers will be based on utility function to choose goods, and retailers need to balance the consumers demand function and profit function themselves, finally arrive at an optimal equilibrium in order to get the maximum profit.

Based on the previous research, consumer behavior has become one of the most important factors that affect pricing mechanism. The focus of this paper is mainly study on influencing factors of consumer strategy behavior of 
retailers pricing mechanism. Specifically, under uncertainty in demand and certainty demand situation, influence strategy behavior of consumers on the prices and profits; and by introducing a discount factor, considering the inventory quantity and consumer demand for different circumstances, purchase decision and dynamic pricing strategies of consumers.

\section{Dynamic Pricing under Consumer Certain Demand Condition}

According to rational economic principles and assumptions in economics, the market price of the product has a great influence on the consumers. For the general phenomenon and the economic principle of the market, the demand is a function of price, the lower the price demand is bigger, so that consumer demand functions is $D(p)$, is a continuous real time function with the change of price $p$, and monotonically decreasing. Assume the sale period into two stages, in the sales cycle, if the sales price of the products is $p_{1}$, in the period two, sales price is $p_{2}$. Because of the existence of value passing, so that $p_{1} \geq p_{2}$. When the products are remaining, will cause a certain degree of inventory backlog, the backlog of cost is set to $\mathrm{k}$, and $p_{1} \geq p_{2} \geq k$.

When consumers in the purchasing process, they price sensitivity are not same, part of consumers price sensitivity are low, do not care about product price, but care products utility; other part of consumers, compared to the final possession, pay more attention to the price of the product, so they will use the strategic behavior. Setting a low price sensitivity of consumers accounted for in the process of consumption ratio is $r$, the sensitivity of high proportion of consumers for 1-r. The consumers focus on price, under electronic commerce, through past purchasing experience of similar products and sales history, promotion information, can probably determine the commodity prices. Therefore, the consumer will wait a reasonable price to buy the product during sales process to obtain the maximum utility of consumption.

\section{Dynamic Pricing Strategy with Timely Replenish Inventory}

When the circumstances of product inventory replenish timely, consumers can not get product and the loss of utility is zero, so for the consumers, will only pay attention to one of the most suitable price to buy goods. Because retailers finally in the sale of the final stages of perishable products, the inventory is the loss to retailers, need to be deducted from the proceeds. For the inventory replenish timely retailers, the inventory quantity will be easier to control, does not appear a large number of inventory situation, so in this case, it supposes the retailers final inventory number influence to income is negligible.
In the first stage, price is $p_{1}$, consumer demand is $D\left(p_{1}\right)$, non-strategic consumers ratio is $r D\left(p_{1}\right)$, the proportion of strategy consumers is $(1-r) D\left(p_{1}\right)$. Strategy consumers will not in the price of $p_{1}$ moment to buy, but will wait until the price to $p_{2}$. When the price of the product change to $p_{2}$, at this time to buy the product not only has the price of $p_{1}$ strategy consumers, there is a part of consumers are willing to pay the price of $p_{2}$, but not willing to pay the price of $p_{1}$. In the two sales stage, the final profit for retailers is,

$$
\begin{aligned}
\pi_{1}= & r D\left(p_{1}\right)+p_{2}\left[(1-r) D\left(p_{1}\right)+\right. \\
& \left.D\left(p_{2}\right)-D\left(p_{1}\right)\right]-k D\left(p_{2}\right) \\
= & r D\left(p_{1}\right)\left(p_{1}-p_{2}\right)+\left(p_{2}-k\right) D\left(p_{2}\right)
\end{aligned}
$$

Retailers set prices $p_{1}$ and price $p_{2}$ according to the profit formula, and finally to obtain the maximum profits. According to the profit formula, we can see the profits of retailers rise with the ratio of non-strategy consumer buying at the first stage price of $p_{1}$.

If the value of the products will decrease with the passage of time, at the same time consumer demand is also the exponential function of price, set the consumer price demand functions is $D(p)=a e^{-b p}$, and $a$ and $b$ are constants. Substitute the price demand function into the profit function, can obtain,

$$
\begin{aligned}
\pi_{1}= & r p_{1} a e^{-b p_{1}}+p_{2}\left[(1-r) a e^{-b p_{1}}+\left(a e^{-b p_{2}}\right.\right. \\
& \left.\left.-a e^{-b p_{1}}\right)\right]-k a e^{-b p_{2}} \\
= & r a e^{-b p_{1}}\left(p_{1}-p_{2}\right)+\left(p_{2}-k\right) a e^{-b p_{2}}
\end{aligned}
$$

According to the first order derivation function, can obtain the maximum profit of retailers in $p_{1}$ and $p_{2}$.

$$
\begin{gathered}
\frac{\partial \pi_{1}}{\partial p_{1}}=r a e^{-b p_{1}}\left(1-b p_{1}+b p_{2}\right)=0 \\
\frac{\partial \pi_{1}}{\partial p_{2}}=r a e^{-b p_{2}}\left(1-b p_{2}+b k-r e^{-b\left(p_{1}-p_{2}\right)}\right)=0
\end{gathered}
$$

Get the optimal price:

$$
\begin{aligned}
& p_{1}^{*}=\frac{1}{b}\left(2+b k-\frac{r}{e}\right) \\
& p_{2}^{*}=\frac{1}{b}\left(1+b k-\frac{r}{e}\right)
\end{aligned}
$$

The maximum profit is:

$$
\pi_{1}\left(\mathrm{p}_{1}^{*}, \mathrm{p}_{2}^{*}\right)=\frac{a}{b} e^{\frac{r}{e}-b k-1}
$$

Assume $a=1$, value passing factor $b=0.5$, and because 
$p_{1} \geq p_{2} \geq k$, set $k=0.7$, then the trend of non-strategy consumers percentage $r$ shown in "Fig. 1".

According the maximum profit expression and trend figure 1 can be seen, with the non-strategy consumer ratio of $r$ increased, the profit will increase, the biggest profit will have a maximum at $r=1$. In this process, the optimal combination of two stages pricing strategy is $\left(p_{1}^{*}, p_{2}^{*}\right)$, according to the expression, with the non-strategy consumer ratio of $r$ increased, the optimal pricing combination gets smaller. When pricing combination reach minimum value at the same time, it gets the biggest profit value.

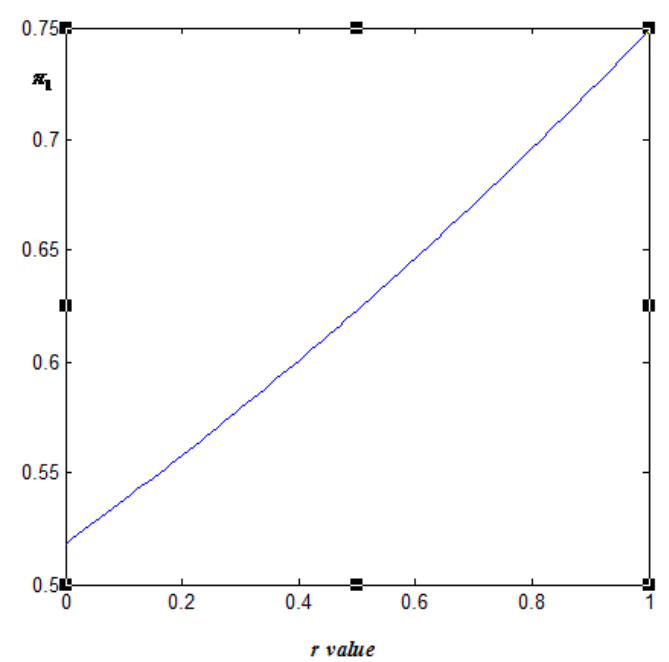

Figure 1. The trend graph of $\pi_{1}$ with $r$ value

\section{Dynamic Pricing Strategy with Fixed Replenish Inventory}

Compared with the inventory is abundant, fixed inventory led to supply limited. Consumers use strategies for product prices will appear the situation of buy nothing, thus loss product utility ultimately. Because of rational behavior of strategy consumers, existence probability product obtained at the same time. Therefore this paper will focus on the probability of purchase goods, do not consider the proportion of consumers. In the rational case, probability appears to make consumers choose their own strategy. At this time, in the face of the shortage risk, strategic consumers need to weigh two stages of purchase decision, in order to obtain the maximum utility in the purchase process.

Assume there are $N$ consumers in the market, and the number is determined. Because of the commodity supply quantity limit, will lead to strategy consumer more and more, so we assume all consumers of this case are strategy consumers. Retention value of goods is $v$, consumers and retailers have the same reservation price distribution function $F(v)$ and the probability density function $f(v)$, set the distribution function $F(v)$ is uniform distribution function on $[0, W]$.
Hypothesis:

1. Retailers will still perform two stage pricing $\left(p_{1}, p_{2}\right)$;

2. If consumers choose to buy in the first stage, will certainly to obtain the product;

3. The second stage of consumers to buy goods with probability g, and value retention ratio is $\delta$ due to postpone the purchase.

In the first stage for sale, consumers access the consumer surplus of $\left(v-p_{1}\right)$; in the second stage the probability of buying goods is g, and consumer value dies, so second stage consumers acquire surplus of $g\left(\delta v-p_{2}\right)$. We have previously assumed that consumers are rational person, so consumers can compare the two stages of consumer surplus to maximize consumer surplus.

\subsection{Consumer Strategy Behavior of Fixed Inventory Situation}

Fixed inventory led consumers will be buying with probability in the second phase, which will affect the consumer surplus. First we consider a critical situation; consumers access the same consumer surplus in the two stages. There, $v-p_{1}=g\left(\delta v-p_{2}\right)$, get consumer retention value: $v=\frac{p_{1}-g p_{2}}{1-g \delta}$. Because of the price and value retention ratio are exogenous and can be perceived, the size of the $g$ uncertainty affects the goods retention value considered by consumer. So we will see $\mathrm{v}$ as a function of $g$ of $v(g)$. According to the function, $v(g)$ is a monotone increasing function. So it gets the boundary value of

$$
v_{0}(g)=\frac{p_{1}-g p_{2}}{1-g \delta} .
$$

Consumers will make the decision based on the boundary condition:

When $v(g)>v_{0}(g)$, consumers will choose to purchase in the first stage;

When $v(g)<v_{0}(g)$, consumers will choose to purchase in the second stage;

According to the function nature and the decision can be concluded: if the product probabilities of $g$ is higher for consumers in the second stage, the gain of consumer in the second stage is larger, then consumers can choose in stage two to buy; if the probability is very small, the consumer will choose to buy in stage one, to avoid the risk of out of stock in the second stage. In the face of this strategy behavior of consumers, retailers need to analyze according to the amount of inventory and potential consumers, so as to give proper pricing decisions to maximize returns.

\subsection{Retailers Pricing Decision under the Condition of Fixed Inventory}

The consumer's strategic behavior will affect the whole stage retailer gains, supposing that the retailer in the sale process always seek maximize profits. Retailers find the balance between price and sales quantity in the other stages, 
so as to obtain the largest profit. Assuming commodity will form certain cost that each item form cost expenditure of $k$, and there is $k<p_{2}<p_{1}$.

Consumers in the purchase process make purchase judgment according to the number of retailers selling trend. If retailer's fixed inventory is $C$, at the same time as the consumer and retailer retained price distribution function is $F(v)$. When price is $p_{1}$, consumers purchase probability is $1-F\left(p_{I}\right)$, consumers buying number is $N\left(1-F\left(p_{I}\right)\right)$; similarly, we can get when the consumers in price $\mathrm{p} 2$, the number of consumers buy for $N\left(1-F\left(p_{2}\right)\right)$. As a result of the purchase amount of the first stage and the second stage have a lot of relational, so inventory $\mathrm{C}$ and comparison will be divided into three situations to discuss.

(1) When the number of the retailer's inventory for $C \leq N\left(1-F\left(p_{1}\right)\right)$

According to the hypothesis, we can judge that the first stage consumers may be the situation of cannot purchase the goods. So in this case, the retailer can sold goods out in the first phase, without waiting for the second phase of the sale price is low. In this case, the goods inventory is very few, the consumer demand of the first phase may not be able to meet, so we will ignore the policy behavior of consumers, there are gains for retailers:

$$
\pi_{21}=\left(p_{1}-k\right) C
$$

(2) When the number of the retailer's inventory for $N\left(1-F\left(p_{1}\right)\right) \leq C \leq N\left(1-F\left(p_{2}\right)\right)$

According to the assumption, after meeting the first stage consumer also can satisfy part of the second stage consumer. That is in the second stage also maybe buy goods, so in this case, can not completely ignore the consumer's strategic behavior. In the second stage set the probability of consumer getting goods is g, discussed in the previous section, we can get the number of consumers to buy the product in the first stage and number is $N\left(1-F\left(v_{0}(g)\right)\right)$, amount to second stages is $C-N\left(1-F\left(v_{0}(g)\right)\right)$ consumers number in the second stage is $N\left(F\left(v_{0}(g)\right)-F\left(p_{2}\right)\right)$. It can be obtained in practice, consumers can be met probability:

$$
g_{0}=\frac{C-N\left(1-F\left(v_{0}(g)\right)\right)}{N\left(F\left(v_{0}(g)\right)-F\left(p_{2}\right)\right)} .
$$

Based on consumer rational expected behavior, retailers' product pricing can be learned in advance, at the same time, consumers buy goods with equal probability. So probability of consumers buying goods in second stage will equal to the actual product probability, which is $g=g_{0}$.

Take the formula (8) into formula (10), we get

$$
g=\frac{(C-N)(1-g \delta) w+N\left(p_{1}-g p_{2}\right)}{\frac{N}{w}\left(\frac{p_{1}-g p_{2}}{1-g \delta}-p_{2}\right)} .
$$

The arrangement is a two order equation about the probability of $g$.

$$
\begin{aligned}
Y(g) & =(1-\delta) N p_{2} g^{2}-\left[(C-N) w \delta+N p_{1}\right] g \\
& +\left[(C-N) g+N p_{1}\right]=0
\end{aligned} .
$$

And,

$$
\begin{gathered}
Y(0)=C-N\left(1-\frac{p_{1}}{w}\right)=C-N\left(1-f\left(p_{2}\right)\right) \geq 0, \\
Y(1)=(1-\delta)\left(C-N\left(1-\frac{p_{2}}{w}\right)\right) \\
=C-N\left(1-F\left(p_{2}\right)\right) \leq 0
\end{gathered}
$$

Where, $(1-\delta) \mathrm{Np}_{2}>0$, so according to the properties of a two order equation can be learned, there is one and only one solution $\mathrm{g} 0$ in $[0,1]$ satisfies the condition. In the first stage, number of products sold is $N\left(1-F\left(v_{0}(g)\right)\right)$; second stage, quantity of goods sold is $N\left(F\left(v_{0}(g)\right)-F\left(p_{2}\right)\right)$, we can get the retailers benefit formula :

$$
\begin{aligned}
\pi= & p_{1} N\left(1-F\left(v_{0}(g)\right)\right)+p_{2} N\left(F\left(v_{0}(g)\right)\right. \\
& \left.-F\left(p_{2}\right)\right)-k C
\end{aligned}
$$

Because of the $\mathrm{N}, \mathrm{C}, \mathrm{w}, \delta$, are external variables, obtained these variables, through the numerical simulation to determine the consumers to obtain $g$ values, and then find a set of reasonable $\left(p_{1}, p_{2}\right)$, so as to get the maximum profit value.

If consumer demand in certain condition number for $N=100, k=0.05$, and $N\left(1-F\left(p_{1}\right)\right) \leq C \leq N\left(1-F\left(p_{2}\right)\right)$, need according to the pricing combination of $\left(p_{1}, p_{2}\right), W=1$, combination of price in $(0,1]$, and $k<p_{2}<p_{1}$. According to the characteristics of probability, the value of $g$ is in $[0,1]$ range, in the numerical simulation, when $p_{2}>0.2$, will not get the required $\mathrm{g}$ value, so we set critical point of $\left(p_{1}, p_{2}\right)$ is 0.2 .

In the determined inventory of $C=80$, in the case of different combinations of pricing, get the $g$ value, as shown in "Tab. 1".

According to table 1 data, we can judge the trend of the $g$ value, rise with the price of $\left(p_{1}, p_{2}\right)$. The higher prices of the first stage, consumers will be more waiting to buy, while the higher price of the second stage, the fewer consumers will wait to second stage to buy, consistent with the strategy consumer choice.

On the assumption case, we can also obtain profit value under different pricing combination, as shown in "Tab. 2". 
Table 1. Numerical simulation result of $g$ value under different pricing combination

\begin{tabular}{lllllll}
\hline $\mathbf{p 2}$ & $\mathbf{0 . 1 0}$ & $\mathbf{0 . 1 2}$ & $\mathbf{0 . 1 4}$ & $\mathbf{0 . 1 6}$ & $\mathbf{0 . 1 8}$ & $\mathbf{0 . 2 0}$ \\
\hline 0.28 & & & & & & \\
0.36 & 0.5194 & 0.5426 & 0.5714 & 0.6096 & 0.6667 & 0.8 \\
0.44 & 0.7132 & 0.7427 & 0.7786 & 0.8246 & 0.8889 & 1 \\
0.52 & 0.8 & 0.8264 & 0.8571 & 0.8939 & 0.9396 & 1 \\
0.60 & 0.8474 & 0.87 & 0.8956 & 0.9248 & 0.959 & 1 \\
0.68 & 0.8769 & 0.8964 & 0.918 & 0.942 & 0.969 & 1 \\
0.76 & 0.8969 & 0.914 & 0.9325 & 0.9528 & 0.9751 & 1 \\
0.84 & 0.9114 & 0.9265 & 0.9427 & 0.9603 & 0.9792 & 1 \\
0.92 & 0.9223 & 0.9359 & 0.9503 & 0.9657 & 0.9822 & 1 \\
1.00 & 0.9309 & 0.9431 & 0.9561 & 0.9698 & 0.9844 & 1 \\
\hline
\end{tabular}

Table 2. Profit value table under different pricing portfolio

\begin{tabular}{|c|c|c|c|c|c|c|}
\hline p2 & 0.10 & 0.12 & 0.14 & 0.16 & 0.18 & 0.20 \\
\hline 0.28 & 18.50 & 19.15 & 19.62 & 19.90 & 19.99 & 19.90 \\
\hline 0.36 & 18.98 & 20.54 & 21.86 & 22.94 & 23.78 & 24.38 \\
\hline 0.44 & 17.38 & 19.58 & 21.54 & 23.26 & 24.74 & 25.98 \\
\hline 0.52 & 13.32 & 16.06 & 18.66 & 21.02 & 23.14 & 25.02 \\
\hline 0.60 & 6.5 & 9.98 & 13.22 & 16.22 & 18.98 & 21.50 \\
\hline 0.68 & -2.78 & 1.34 & 15.22 & 8.86 & 12.26 & 15.42 \\
\hline 0.76 & -14.62 & -9.86 & -5.34 & -1.06 & 2.98 & 6.78 \\
\hline 0.84 & -29.02 & -23.62 & -18.46 & -13.54 & -8.86 & -4.42 \\
\hline 0.92 & -45.98 & -39.94 & -34.14 & -28.58 & -23.26 & -18.18 \\
\hline 1.00 & -65.50 & -58.82 & -52.38 & -46.18 & -40.22 & -34.5 \\
\hline
\end{tabular}

When the price $p_{1}$ is fixed, the profit $\pi$ will increase and then decrease with second stage price $p_{2}$, there will be an extreme point. At the same time when $p_{2}$ is fixed, the profit value also has the existence of first increase and then decrease. According to the data in the table, if the first stage pricing is relatively high, profits will rarely, this shows that when $p_{1}$ higher, will cause the strategy consumers more choice to wait, make consumers more choices purchase in the second phase, which in the table can be explained. If the first stage pricing too low, the first phase of consumers will increase, but the retailer would lose some profits. On the other hand, if the second stage is low, it would increase the consumer surplus of stage two , more consumers wait, and more customers originally should purchase in the stage one choose to wait to buy in stage two. According to the Fig. 1 and Tab. 2 display, the second phase price of $p_{2}=0.2$ is the most reasonable for retailers, for different $p_{1}$, all can obtain the maximum value.

According to the profit value under different price combination, we can get an interpolation map of $p_{1}, p_{2}, \pi$ shown in "Fig. 2" below.

In the above assumption, according to the simulation result, we can find the maximum profit value is 25.98 , the corresponding price combination $\left(p_{1}, p_{2}\right)$ is $(0.44,0.2)$, corresponding to the consumer can obtain product probability is $100 \%$ at the second stage.

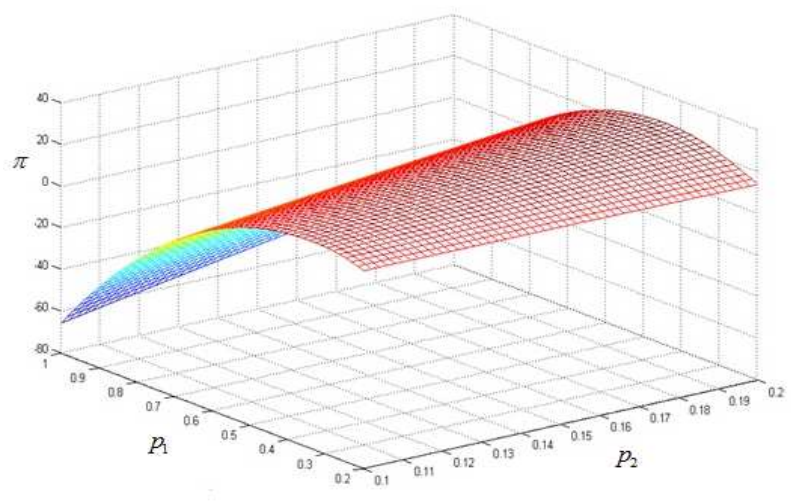

Figure 2. Distribution of profit value under different price combination

(3) When the number of the retailer's inventory for $C \geq N\left(1-F\left(p_{2}\right)\right)$

This means after retailers meeting consumer two stages, product inventory still exist surplus. The retailer has some surplus inventory after meeting the needs of consumers that forms certain cost. As each item cost expenditure is $\mathrm{k}$, and there is $k<p_{2}<p_{1}$.

When consumer strategy behavior is not considered in the retailer's case, it specifies a two phase of the price strategy $\left(p_{3}, p_{4}\right)$, the return formula for retailers is: 


$$
\begin{aligned}
\pi & =p_{3} N\left(1-F\left(p_{3}\right)\right)+p_{4} N\left(F\left(p_{3}\right)-F\left(p_{4}\right)\right)-k C \\
& =\frac{N}{w}\left(w p_{3}-p_{3}^{2}+p_{4}\right)-\frac{N}{w} p_{4}^{2}-k C
\end{aligned}
$$

According to the properties of the equation, respectively for the first order partial derivatives, so as to obtain the maximum benefit, retail negotiate a price: $p_{3}=2 / 3 w$, $p_{4}=1 / 3 w$. In the implementation of this pricing strategies, retailers ignore the strategic behavior of consumers, but strategy consumers still exist, the stage critical retention value for consumer is

$$
v(1)=\frac{p_{3}-p_{4}}{1-\delta}=\frac{w}{3(1-\delta)} .
$$

The buying number of the first stage is

$$
N(1-F(v(1)))=N\left(1-\frac{1}{3(1-\delta)}\right) .
$$

The purchase amount in second stage is

$$
N\left(F(v(1))-F\left(p_{4}\right)\right)=N \frac{w}{3(1-\delta)} .
$$

When the consumers' value passed factor $\delta \geq 2 / 3$, in the first stage the number of consumers purchase is zero, and eventually benefit is $\pi_{1}=2 / 9 w N-k C$; when the value passing factor $0 \leq \delta \leq 2 / 3$, there all exist consumers in the first and second stages, the ultimate retailers profit is

$$
\pi_{2}=\frac{4-5 \delta}{9(1-\delta)} w N-k C .
$$

Retailers consider consumer strategy behavior in the sale process. The critical keep value of products for both two stages is $v\left(\mathrm{~g}_{0}=1\right)=\frac{p_{1}-p_{2}}{1-\delta}$. Consumers will buy the product in stage one when reservation price more than $v\left(\mathrm{~g}_{0}=1\right)$, otherwise they will buy in stage two. The retailers' income function is

$$
\begin{aligned}
\pi=p_{1} N(1- & \left.F\left(v_{0}(1)\right)\right)+p_{2} N\left(F\left(v_{0}(1)\right)-F\left(p_{2}\right)\right)-k C \\
\pi_{\max }= & p_{1} N\left(1-F\left(v_{0}(1)\right)\right)+p_{2} N\left(F\left(v_{0}(1)\right)\right. \\
& \left.-F\left(p_{2}\right)\right)-k N\left(1-F\left(p_{2}\right)\right)
\end{aligned}
$$

Because $v_{0}(1)=\frac{p_{1}-p_{2}}{1-\delta}$, bring it into formula (22), than get the first order derivative. Let $y=\pi_{\max }$, when $k=p_{2}$, reach $y_{\min }$. We can $p_{1}-p_{2}=\frac{1}{2} w(1-\delta)$ get for the first order derivative function. Then, $y_{\min }=\frac{1}{4} w N(1-\delta)$. When $k=0$, we can get the profit maximizing price: $p_{1}=(1-2 / \delta) w, p_{2}=2 / w$, put it into the profit equation can get the maximum profit is

$$
y_{\max }=\pi_{\max }=\frac{2-\delta}{4} w N
$$

We can get there $\pi_{\max } \geq \pi_{2} \geq \pi_{1}$, the retailer will consider the strategy of consumer behavior, so that the final return is $\pi_{\text {max }}$. This shows the retailer cannot ignore the strategic consumer behavior in the process of pricing. At the same time according to the income equation we can see, the discount factor of consumer value has great influence on income. The discount factor is high, consumers believe in second stage goods value will be lower, so consumers wait to buy will be more intense. This caused consumers in the first phase of the willing to pay the price is low, ultimately affect the retailer's revenue.

When $\mathrm{k}$ value is not high, and approaches zero, neglected in the case, the first stage revenue is $\pi=p_{1} N\left(1-F\left(v_{0}(1)\right)\right)$, put the first phase optimal price into revenue can get

$$
\pi=p_{1} \frac{N}{2}=\frac{2-\delta}{4} w N
$$

We can see that the retailer's income in the second stage is zero, while the sales number of the second stage is also zero. In the two stage pricing announced in retail, make its returns are present in the first stage, so higher prices keep buying in the first stage, reduce strategy consumer, decrease the purchase number of the second stage, lower consumer's price expectations, try to change two sales cycle into one sales cycle, reduce retailers' profit loss by consumer's strategic behavior. In the higher value of $\mathrm{k}$, at the same time is relatively large, retailers will need to weigh the pricing strategy, so that the revenue maximization.

In the fixed inventory circumstance, retailers' decisions would be made based on comparison of inventory and consumers demand. In the retailer's inventory level cannot meet consumer demand in stage one, retailers adopt pricing strategies to obtain more profits; on the retailer's inventory levels to meet part of consumers' demand in stage one and cannot meet all the consumers' demand, retailers need to seek a reasonable two stage pricing, to obtain the maximum profits; when the inventory quantity is large enough to meet all the demand of consumers, retailers should adopt appropriate pricing strategy, as much as possible to allow consumers to buy the product in the first stage.

\section{Conclusion}

Retailers face some strategy consumers; consumers will buy goods according to the maximum utility of two stage process. Because retailers face consumer uncertainty, at the same time, the retailer's inventory is starting from the view of revenue management, if consumers can buy in the second stage that the utility must higher than the first phase 
purchase utility, but at the same time maybe consumer purchase nothing in the second stages, it will reduce the consumer utility of the second phase purchase. Retailers using two stage pricing model, consider the consumers two stages pricing strategy, change price to change the probability of consumer in the second stage purchase, thus to reduce the consumer's strategic behavior. In the course of this study, it divides into two condition of consumer demand determination. In determined demand case, the retailer is divided into inventory can be added timely manner and cannot timely supplied to discuss. So as to the consumer demand is uncertain, and respectively discusses the retailers' pricing strategy in these cases.

\section{Acknowledgements}

The study is supported by Beijing Wuzi University scientific research base of science and technology innovation platform of modern logistics, information and control technology research (project code: PXM2014_014214_000086).

\section{References}

[1] Elmaghraby W, Keskinocak P. "Dynamic Pricing in the Presence of Inventory Considerations:Research Overview, Current Practices, and Future Directions", Management Science, vol.49,pp1287-1309, Oct 2003.

[2] Zhou Yongpin, Fan Ming, Cho Minho. "On the threshold purchasing behavior of customers facing dynamically priced perishable products", Presentation at Informs Pittsburgh National Meeting, Nov 2006.

[3] Aviv Y, Pazgal A. "Optimal Pricing of Seasonal Products in the Presence of Forward-Looking Consumers", Manufacturing \& Service Operations Management, vol.4, pp.1-21,Jan 2008.

[4] Peng Zhiqiang, Xiong Zhongkai, Li Gendao. "The Inter-temporal Pricing and Price Match Mechanism with Strategic Customers", Journal of Industrial Engineering and Engineering Management, vol.24,pp.53-57, April 2010.

[5] Cheng Yan. "Delay buying behavior-oriented perishable products dynamic bundling strategy in e-commerce setting", Systems Engineering Theory \& Practice, vol.31, pp. 1892-1902,Oct.2011.

[6] Dou Jinhu Tian Peng. "Research on the effect of perishable goods' depreciation on dynamic pricing". Shanghai Management Science, vol.33, pp.40-43,Jan 2011. 